\title{
OFFLINE REKSO RELEASE 6 CAT AND ENCARTA ENCYCLOPEDIA AS \\ A TOOL IN TRANSLATION TEACHING
}

\author{
Budiarto \\ Foreign Language High School (STIBA) IEC Jakarta, Indonesia \\ E-mail: budiarto@stibaiec-jakarta.ac.id
}

APA Citation: Budiarto.(2018). Offline Rekso Release 6 Cat And Encarta Encyclopedia As A Tool In Translation Teaching. Journal of English Language and literature, 3(2), 1-10.doi: 10.37110/jell.v3i2.48.

Published:01-09-2018

\begin{abstract}
The present study is to focus on the use of Offline Rekso Release 6 CAT (Computer Aided Translation (CAT) systems) and Encarta Encyclopedia software as a tool in translation teaching. It is true that students have to apply their theory through translation process by making use of dictionaries. However, both translation theory and dictionaries are still not enough to accelerate the translation process, even when they can derive meaning from context. This study is based on a brief theoretical literature overview, classroom activities and observation. The findings suggest that offline Rekso release $6 \mathrm{CAT}$ and encyclopedia software are a tool that can help translation teaching.
\end{abstract}

Keywords: translation teaching, tool, offline, CAT, and encyclopedia

\section{INTRODUCTION}

The use of dictionary might help translation process despite the fact that students can get meanings from context, but relying heavily on both of them could be a slow process. Sometimes a paragraph containing to many difficult words takes longer time to process. This especially happens when students have to guess unfamiliar words in other fields of science beyond their schemata. It is true that they can make use of a dictionary and select which meaning is the most appropriate in a particular context, but this sometimes does not help or takes much time. For instance, the meaning in context of medical science could be different from the one of information technology. Translation process is such a long process as they have to implement the right steps based on the theory, recognize words based on which context of science or culture, and 


\section{Budiarto}

Offline Rekso Release 6 CAT and Encarta Encyclopedia as a Tool in Translation

understand differences of grammar and culture of languages involved as well as other information or knowledge. It indicates that good grammar and vocabulary acquisition in both languages cannot guarantee the success of translation process. Students might fail to interpret certain text even when they opt for the right dictionary to cross check the meaning in a paragraph. For example, students select the approriate meaning of words about medical science, and it might help for several sentences, but not for the overal meaning of the paragraph. There is extra meaning, background knowledge and information that students need to find out if they want to get better result. Such background knowledge is often found in a complete encyclopedia software such as Encarta.

Translation requires not only general reading but also the close one. Meaning is not just replacement of corresponding words since a word might need further explanation which can be obtained from an unabridged dictionary or an encyclopedia (Newmark, 1988). It is necessary to use various kinds of dictionary according to certain purposes. A dictionary can be monolingual or bilingual available in print, in $\mathrm{CD}$ ROM, or online. It can also abridged or unabridged, so when the meaning is still not suitable, an unabridged dictionary might be the solution. However, since a source text contains specialized area, it requires selection of dictionary based on the science background. When it is not enough, sometimes an encyclopedia is needed. Littman states that there are two types of dictionary, the printed and electronic ones, which can be available on-line, hand-held or on the CD-ROM (Litman, 2006).

In fact translation practice can be seen as activities inducing deeper insight into texts in order to be more meaningful.This is in line with the objectives of the study stating that translation activities should raise awareness of language use and examine the usefulness encyclopedia software to provide background knowledge. Since the time it takes is important, the use of CAT also should be taken into considertaion. The method of this study is based on the theoretical background, practice of translation and observation.

Schaffner (1998) suggests that translation activities need to be taught in foreign language classrooms because they can help students to improve verbal skills, acquire new vocabulary, develop language style, know how languages work, activate L2 grammar, and check their comprehension of L2.

Unfortunately, translation used to be ignored in foreign language classes as it was viewed as activities which did not improve learners' language competence. It is not 
completely true because some scholars still can show its benefits through their research. Ross (2000) says that translation is the fifth language skill which can boost students to communicate and use social skill. In a real situation, people translate a text not only for its meaning, but they interact and communicate to ensure that the result of translation is suitable when it is used. It is why translation is well suited to be implemented in foreign language classroom as in the real life such situation might occur (Schaffner, 1998).

Despite its support from Ross (2000) and some other reserachers, many teachers still do not think that translation can promote communication in foreign language. They think that through translation activities, students cannot maximize the use of target language since there is a lot of interference from L1.

It is not completely true that translation is merely L 1 interference when we deal with the real situation. For example, a tourist might translate information into his or her mother tongue when eager to know the meaning of the text in road signs, brochure, and local newspaper. Then, he or she might prove whether the meaning is correct by interacting with the local people. As Google translate is very easy and can translate so many languages, they might want to get the most current information directly from the original one to be translated.
Employees in international companies or those from five star hotels might deal with translation because they need documents to be understood in both languages. They may write or print announcements of events to be understood by local and foreign tourists. Even most people around the globe need translation when they make friends with people from different countries although they are not a competent language users. They make a lot of errors, but they do communicate using sosial media through translation, and the understanding caused by translation is often reduced as the communication is becoming more intensive (Ross, N.J).

Perkins (1985) suggests that to raise students' linguistic awareness, they might need to be able to contrast between L1 and L2 grammatical structures, and be familiar with them, so that interlingual interference can be anticipated. Contrasting both source and target texts often includes the understanding of authentic materials from source text.

Duff (1994) indicates that translation can be brought into classrooms based on real social activities. The students can translate emails from friends or relatives from overseas, important documents to study abroad, favorite songs or news headlines.

Translation requires the integration of at least reading and writing. It encourages students to 


\section{Budiarto}

Offline Rekso Release 6 CAT and Encarta Encyclopedia as a Tool in Translation

interact in groups or with the teacher while discussing their translation. The active participation during translation might also lead to listening to others and telling others in foreign language being translated from mother tongue. It means that translation is not an isolated activity.

On the other hand, in business, the most common complaint in translation service is the slow process of translating documents. This often happens for example when a client wants his document containing 40 pages to be completed within 2 days. A client normally only thinks about business without considering that translation is not simple process and takes a lot of time in order to be perfect. A client frequently wants the result submitted before a date line with great accuracy and clarity. On the other hand, human translators are often overwhelmed with tons of translation tasks and they try to accomplish them using techniques which take long time. The business world that makes translators frustrated, has urged the use of translation software to be developed suitable for their needs. Although the process may take less than a second to translate a long paragraph, the result still needs editing. Translation software can accelerate the process and reduce the translator's burden when quick translation service is the main issue (Robinson, 2007).
Students should be aware that as they become translators, they must translate not only accurately but also quickly. Translation activities in the classroom can be facilitated with the use of Computer Aided Translation (CAT) systems and encyclopedia software. In addition, CAT should be introduce because time to translate and time allocated in teaching translation are main issues that should be taken into consideration by teacher and students. Online CAT and encyclopedia can be the most up to date tools, but the stability of translation process is often hindered by weak signal to access. Translation class is normally 90 minutes, but activities such as calling the role, giving instruction, and preparing over head projector might reduce the time allocated by about 10 minutes or sometimes more. In other words there are approximately 60 minutes left that should be used wisely. The introduction of CAT makes teacher realize that time management in the classroom is important. Furthermore it will be useful for students when they deal with translation business (Leonardi, 2009).

It is important to note that the main function of MT (Machine translation) is to replace human translators. It does not need human translators at all, so people just type or copy paste documents into MT and translation result can be obtained within seconds. Although MT is 
getting easier to access and getting cheaper and many can be obtained for free, the results are usually not accurate. To compensate the balance between the expertise of human translations and the fast MT, Computer Aided Translation (CAT) systems have emerged. CAT is mainly designed to produces a rough draft, which should depend on human posttranslation process to edit or revise for greater accuracy (Samuelsson, 2010). No translation can be produced without translators, even sophisticated fully-automated machine cannot be operated without users' involvement to insert text and revise it (Munday, 2010).

\section{RESULTS AND DISCUSSION}

Teaching translation using CAT seemed to offer students a tool to speed up the translation process. There was approximately an hour dedicated to teaching translation, so using the internet might delay the process of translation, especially when the signal was not strong enough. Both CAT and Encyclopedia could run online or offline, but as the trouble might arise, the offline one was preferable. The presentation of translation theory by teacher lasted for about 20 minutes. 10 minutes was used to practice some samples of sentences from related theory to be translated, and the other 30 minutes was used to translate a paragraph. While translating a paragraph, the students were encouraged to use the RR6 and Encarta.

Though students were able to copy and paste the whole paragraph or some sentences to RR 6, they tended to select sentences or parts that they did not really understand. Here is an example when some sentences were translated. Despite some mistakes it made, it was equipped by editing tool. It enebled students to update the dictionary in it, so that the same mistakes will not occur anymore.

RR6 was equiped with word by word translation. It is useful when students are trying to analyze the errors from this tool. By using this tool, students were involved in editing and translating process using CAT. The speed was needed, but the students were not allowed to ignore the mistakes. It could be the source of analaysis and learning for students.

\begin{tabular}{|c|c|c|c|c|}
\hline 8 & d9- 9 & 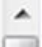 & mother & $\mathrm{nn}-2$ \\
\hline The & $\mathrm{db}-9$ & & here & di sini c9-9, \\
\hline red-clothed & red-clothed ad- 5 & $\equiv$ & now & sekarang \\
\hline girl & Gadis no- 2 & \multirow[b]{4}{*}{-} & \multirow{4}{*}{\multicolumn{2}{|c|}{$\begin{array}{l}\text { have been telah hvP9 } \\
\text { grown up orang dewasa nn- } 2 \\
\text { and } \quad \text { dan } 0 \text { - } 9 \\
\text { looked dilihat v3P } 9\end{array}$}} \\
\hline who & yang $09-9$ & & & \\
\hline & duduk v3x 9 & & & \\
\hline \multicolumn{2}{|c|}{ beside di samping db- 9} & & & \\
\hline
\end{tabular}




\section{Budiarto}

Offline Rekso Release 6 CAT and Encarta Encyclopedia as a Tool in Translation

Students could use a bilingual dictionary, but the more accurate description and examples of authentic sentences were definitely needed. Besides using M.Echols-Hasan Saddily dictionary (bilingual) dictionary, the students could use monolingual dictionary from Encarta. This was especially done to make the students get the exposure of its use by the native speaker of English which could also help them to write or translate into English.

In addition to monolingual dictionary and RR6, an encyclopedia accompanied students in the translation process. Through the use of Encyclopedia, the students could get more knowledge from so many topics

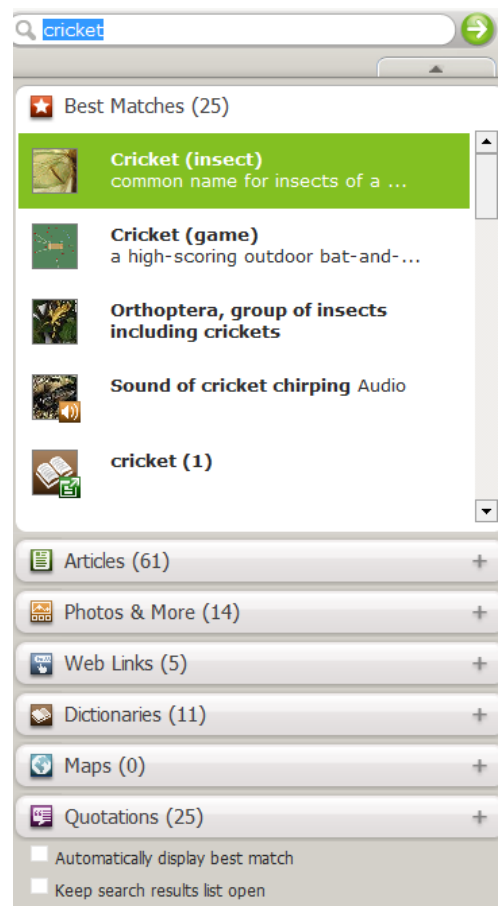

or fields of science. The following is the screenshot of finding the meaning of "cricket" which can be a kind of insect or a kind of game. The additional description about "cricket" from the encyclopedia could help them to understand a certain concept, but the time needed to look up more information was usually whithin short period of time.

When they were curious and wanted more information, they were allowed to do so as long as there was enough time to accomplish the transation task. As their curiousity was growing, they could browse more related article. As it was offline, the process to find the article they were interested in was so easy and fast.

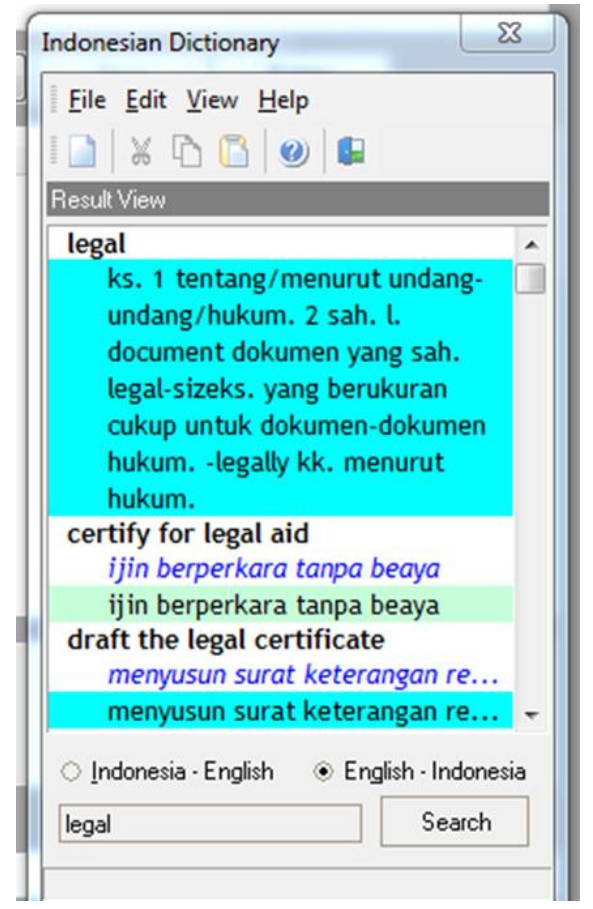




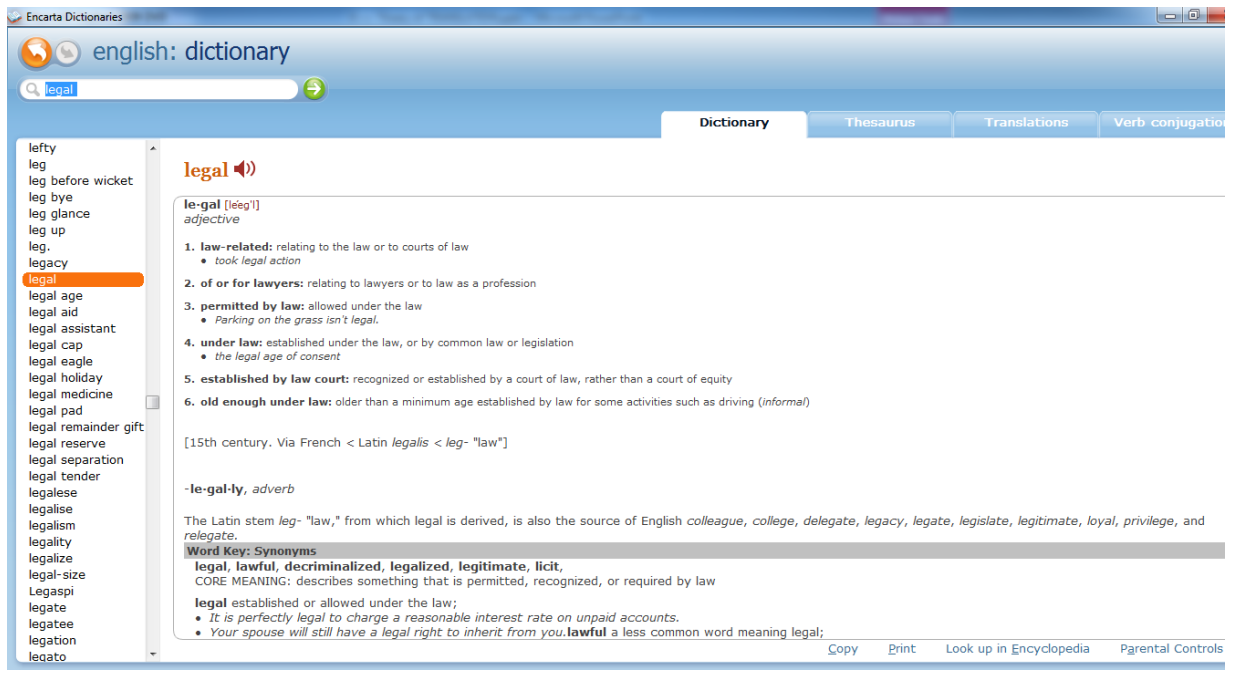

Whenever the whole text was translated, they were not satisfied with the results, especially as they got more experience; they preferred using RR6 when necessary. However, when the topic was unfamiliar, they resorted to using RR6. Notwithstanding, it was done to get the general idea, not the final draft of their translation. From the screen shot, it is clear that the tool made a lot of mistakes. For example, the word "Graft" should have been translated into "pemotongan" as the monolingual dictionary says "Graft is a piece of healthy skin or bone cut from one part of a person's body and used to repair another damaged part, or a piece cut from one living plant and fixed to another plant so that it grows there."

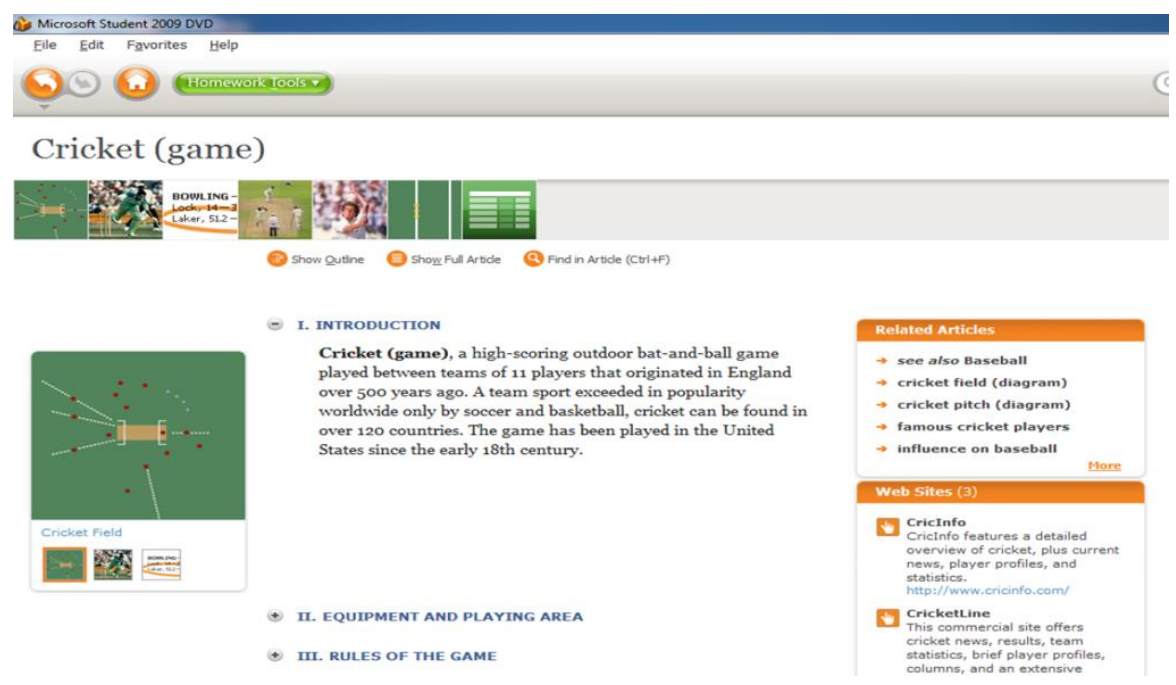




\section{Budiarto}

Offline Rekso Release 6 CAT and Encarta Encyclopedia as a Tool in Translation

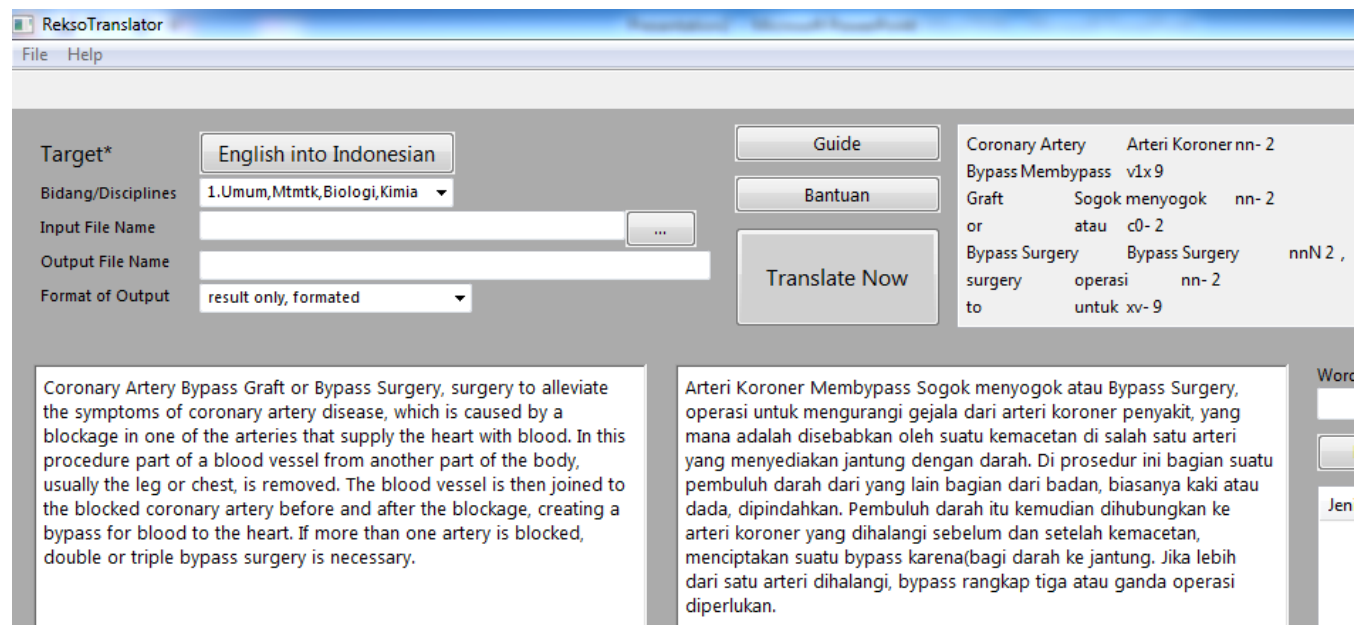

As soon as they got the general idea, they translated again with their own words. This was especially done because they did not want to depend on the RR6 wholly. They still found RR6 beneficial, but apparently the excessive use of it would ignore the theory or procedures of translation they acquired during the semester. The lecturer saw that the balance use of the tool an theory had to be preserved.

The students were curious about the use of specialized dictionary inside RR6. Its function is not only to provide meaning in certain fields of science, but also to translate as many texts the students want. As the students managed to identify what field of science it was, they decided which one to be used to translate.
RR6 was 60 per cent accurate, so it could help students to get the main ideas before editing process. For the detail information, around 4 or 5 in 10 sentences seemed awkward and sometimes lead to misinterpretation. They tried to search the most appropriate meaning from English to Indonesian dictionary or vice versa. Based on the observation around 5 out of 10 sentences were able to be translated using this kind of dictionary. This occurrence was resulted from the absence of particular words that they were searching from that bilingual dictionary. In this situation they chose monolingual dictionary as it was more comprehensive than the bilingual one. Encarta Encyclopedia was in one package with a monolingual EnglishEnglish dictionary. It provides more 
elaborated description of the meaning and with more samples of sentences. In addition, the real use of a particular word appeared in articles of the encyclopedia. It also gives information about culture, social and economic conditions and various topics. Furthermore, pictures, diagrams or videos were also included with the description of it requires audio visual aids.

In addition to using RR6, the use of Encarta may compensate the problems with translation, especially regarding the speed of process.

\section{CONCLUSION}

The introduction of RR 6 and Encarta software is essential in order that the students know other aspects in translation. RR6 helps students to make the translation process run more quickly. However, as the result from RR6 is not perfect, students' analytical thinking is encouraged. The can edit, add more entry in to the dictionary and revise their work. Encarta encyclopedia equiped with monolingual dictionary can solve students' problem when the result from bilingual dictionary is not quite satisfactory. In addition as the time management is important, using the softwares offline is the priority.

However, further investigation must be carried out as the accuracy of such tools needs to be upgraded as new versions emerge and the access from the internet can be perfect in the future. As the participants involved were only 5 , other research with more participants has to be hold. This research is limited to the sophomores majoring in English literature, so the findings cannot be generalized.

\section{BIBLIOGRAPHY}

Newmark, Pete. 1988. A Textbook of Translation. New York, Prentice Hall International.

Schaffner, C. 1988. Qualification for Professional Translators:

Translation in Language Teaching Versus Teaching Translation. Manchester, St. Jerome publishing.

Ross, N.J. Interference and Intervention: Using Translation in the EFL Classroom, Modern English Teacher, No 9(3). pp.6166.

Perkins, C., 1985. Sensitizing Advanced Learners to Problems of L1-L2 Translation inTitford, C. \& Hieke, A. E., Translation in Foreign Language Teaching and Testing. Tubingen: Narr, pp.5872.

Duff, A.1991. Translation: Resource Books for Teachers. New York, Oxford: Oxford University Press. 


\section{Budiarto}

Offline Rekso Release 6 CAT and Encarta Encyclopedia as a Tool in Translation

Robinson, Douglas. 2007. Becoming a Translator: An Introduction to the Theory and Practice of Translation. London, Routledge.

Leonardi, V., 2009. Teaching Business English through Translation., Journal of Language \& Translation, 10(1), pp. 139-153.

Robinson, Douglas. 2007. Becoming a Translator: An Introduction to the Theory and Practice of Translation. London, Routledge.

Leonardi, V., 2009. Teaching Business English through Translation.,
Journal of Language \& Translation, 10(1), pp. 139-153.

Samuelsson-Brown, Geoffrey. 2010. A Practical Guide for Translators. Canada, Multilingual Matters.

Munday, Jeremy. 2010. Introducing Translation Studies: Theories and applications. New York, Routledge.

Littman,B.(2006). Selecting A Dictionary. Retrieve, June 25, 2007, http://www.elearnaid. com/dictionaries.html. 